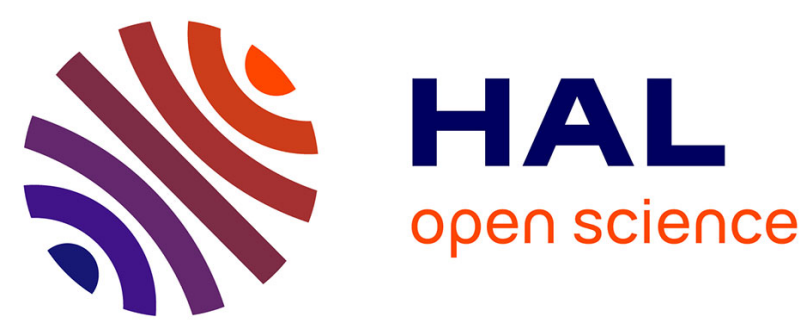

\title{
Low Doses of Bisphenol A Induce Gene Expression Related to Lipid Synthesis and Trigger Triglyceride Accumulation in Adult Mouse Liver
}

Alice Marmugi, Simon Ducheix, Frédéric Lasserre, Arnaud Polizzi, Alain Paris, Nathalie Priymenko, Justine Bertrand-Michel, Thierry Pineau, Hervé Guillou, Pascal G.P. Martin, et al.

\section{To cite this version:}

Alice Marmugi, Simon Ducheix, Frédéric Lasserre, Arnaud Polizzi, Alain Paris, et al.. Low Doses of Bisphenol A Induce Gene Expression Related to Lipid Synthesis and Trigger Triglyceride Accumulation in Adult Mouse Liver. Hepatology, 2012, 55 (2), pp.395-407. 10.1002/hep.24685 . hal-01019497

\author{
HAL Id: hal-01019497 \\ https://hal.science/hal-01019497
}

Submitted on 29 May 2020

HAL is a multi-disciplinary open access archive for the deposit and dissemination of scientific research documents, whether they are published or not. The documents may come from teaching and research institutions in France or abroad, or from public or private research centers.
L'archive ouverte pluridisciplinaire HAL, est destinée au dépôt et à la diffusion de documents scientifiques de niveau recherche, publiés ou non, émanant des établissements d'enseignement et de recherche français ou étrangers, des laboratoires publics ou privés. 


\title{
Low Doses of Bisphenol A Induce Gene Expression Related to Lipid Synthesis and Trigger Triglyceride Accumulation in Adult Mouse Liver
}

\author{
Alice Marmugi, ${ }^{1,2}$ Simon Ducheix, ${ }^{1,2}$ Frédéric Lasserre, ${ }^{1,2}$ Arnaud Polizzi, ${ }^{1,2}$ Alain Paris, ${ }^{3}$ \\ Nathalie Priymenko, ${ }^{1,2}$ Justine Bertrand-Michel, ${ }^{4}$ Thierry Pineau, ${ }^{1,2}$ Hervé Guillou, ${ }^{1,2}$ \\ Pascal G.P. Martin,, ${ }^{1,2}$ and Laila Mselli-Lakhal ${ }^{1,2}$
}

Changes in lifestyle are suspected to have strongly influenced the current obesity epidemic. Based on recent experimental, clinical, and epidemiological work, it has been proposed that some food contaminants may exert damaging effects on endocrine and metabolic functions, thereby promoting obesity and associated metabolic diseases such as nonalcoholic fatty liver disease (NAFLD). In this work, we investigated the effect of one suspicious food contaminant, bisphenol A (BPA), in vivo. We used a transcriptomic approach in male CD1 mice exposed for 28 days to different doses of BPA $(0,5,50,500$, and $5,000 \mu \mathrm{g} / \mathrm{kg} / \mathrm{day}$ ) through food contamination. Data analysis revealed a specific impact of low doses of BPA on the hepatic transcriptome, more particularly on genes involved in lipid synthesis. Strikingly, the effect of BPA on the expression of de novo lipogenesis followed a nonmonotonic dose-response curve, with more important effects at lower doses than at the higher dose. In addition to lipogenic enzymes (Acc, Fasn, Scd1), the expression of transcription factors such as liver $\mathrm{X}$ Receptor, the sterol regulatory element binding protein-1c, and the carbohydrate responsive element binding protein that govern the expression of lipogenic genes also followed a nonmonotonic dose-response curve in response to BPA. Consistent with an increased fatty acid biosynthesis, determination of fat in the liver showed an accumulation of cholesteryl esters and of triglycerides. Conclusion: Our work suggests that exposure to low BPA doses may influence de novo fatty acid synthesis through increased expression of lipogenic genes, thereby contributing to hepatic steatosis. Exposure to such contaminants should be carefully examined in the etiology of metabolic diseases such as NAFLD and nonalcoholic steatohepatitis. (НЕPATOLOGY 2012;55:395-407)

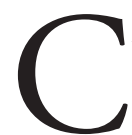
Thanges in diet and lifestyle are leading causes for the emergence of the metabolic diseases associated with obesity. Recently, the hypothesis that a number of food contaminants acting as endocrine-disrupting chemicals may influence metabolic diseases has been proposed. ${ }^{1}$
Bisphenol A (BPA) is an endocrine disruptor highly prevalent in our environment. It is used as the monomer of polycarbonate plastics and epoxy resins. ${ }^{2}$ The human population is widely exposed to low levels of BPA, primarily by way of the diet by migration from food and beverage containers. ${ }^{2} 93 \%$ of urine samples

Abbreviations: Acc, acetyl-CoA carboxylase; BPA, bisphenol A; ER, estrogen receptor; FA, fatty acid; Fasn, fatty acid synthase; NAFLD, nonalcoholic fatty liver disease; NASH, nonalcoholic steatohepatitis; PPAR, peroxisome proliferator-activated receptor; Scd1, stearoyl-CoA desaturase-1.

From the ${ }^{1}$ INRA, TOXALIM (Research Centre in Food Toxicology), Toulouse, France; ${ }^{2}$ Universite de Toulouse, INP, UPS, TOXALIM, Toulouse, France; ${ }^{3}$ INRA, Métarisk, Paris, France; and ${ }^{4}$ MetaToul, Plateau de lipidomique, INSERM, Toulouse, France.

Received April 20, 2011; accepted August 31, 2011.

Supported by grants from the ANR (PNRA-PlastImpact program and CES PerinaTox program) and by the INRA-FORMAS France-Sweden cooperative program. A.M. is funded by a grant from INRA Animal Health Department and the Région Midi-Pyrénées. S.D. is funded by a grant from the Ministère de l'Enseignement Supérieur et de la Recherche.

Address reprint requests to: Pascal G.P. Martin, ToxAlim UMR1331 INRA/INPT/UPS, Integrative Toxicology o Metabolism group, 180 chemin de Tournefeuille, BP 93173, 31027 Toulouse Cedex 3, France. E-mail: Pascal.Martin@toulouse.inra.fr; fax: +33 561285310.

Copyright $@ 2011$ by the American Association for the Study of Liver Diseases.

View this article online at wileyonlinelibrary.com.

DOI 10.1002/hep.24685

Potential conflict of interest: Nothing to report.

Additional Supporting Information may be found in the online version of this article. 
collected from the National Health and Nutrition Examination Survey (NHANES III) cohort revealed detectable levels of BPA. ${ }^{3}$ As a protective measure the U.S. Environmental Protection Agency and the European Food Safety Agency have established a tolerable daily intake (TDI) of $50 \mu \mathrm{g} / \mathrm{kg} /$ day derived by applying an uncertainty factor of 100 to the no-observedadverse-effect level (NOAEL) of $5,000 \mu \mathrm{g} / \mathrm{kg} / \mathrm{day}$ mainly based on liver and reproductive toxicity. However, recent animal studies revealed that exposure to environmentally relevant BPA doses below the TDI alters biological functions such as reproductive functions, brain functions, and metabolic processes by interfering with endocrine signaling pathways. ${ }^{4}$

Recent epidemiological studies showed an association between urinary levels of BPA and the prevalence of diabetes, cardiovascular diseases, and elevated markers of liver toxicity. ${ }^{5,6}$ These studies pointed to metabolic disorders as a potential impact of exposure to low doses of BPA. In agreement with this hypothesis, experimental evidence has accumulated that BPA can alter several aspects of metabolic functions in rodents. Animal studies showed an increased body weight in offspring of mothers exposed to BPA during gestation and/or lactation period. ${ }^{7}$ The increase in body weight was more pronounced and persistent in females than males and the effects were stronger at low compared with high doses of exposure. Such nonmonotonic dose-response relationship have been reported for many actions of BPA. ${ }^{8-11}$ How perinatal BPA exposure may exert these effects remains to be determined, but potential target tissues of BPA action including adipose tissue and pancreas have been studied. Gestational exposure to BPA was shown to increase adipose tissue mass at weaning associated with adipocyte hypertrophy and overexpression of lipogenic genes. ${ }^{9,10,12}$ Low BPA doses were also shown to increase leptin and to decrease adiponectin secretion. ${ }^{9,13}$ In vitro studies documented an increased lipid accumulation and adipocyte differentiation after exposure of $3 \mathrm{~T} 3 \mathrm{~L} 1$ preadipocytes to $\mathrm{BPA}$ and other endocrine-disrupting chemicals. ${ }^{14-16}$

Nadal and colleagues showed that BPA increases insulin synthesis and secretion with concurrent impacts on glucose homeostasis. ${ }^{17,18}$ In vivo injection of 1,10 , or $100 \mu \mathrm{g} / \mathrm{kg} /$ day of BPA to adult male mice resulted in a significant dose-dependent decrease in glycemia in parallel to an increase in insulin from 30 minutes after injection. ${ }^{19}$ Isolated islets of pancreatic $\beta$-cells exposed to a range of BPA doses showed increased insulin content following an inverted U-shape dose-response curve. $^{20}$ The same group recently reported on similar effects in pregnant mice and their offspring exposed to 10 or $100 \mu \mathrm{g} / \mathrm{kg} /$ day of BPA. $^{21}$

Thus, both the adipose tissue and the pancreas have emerged as important targets of low BPA doses. Despite the important roles of the liver in whole body energy homeostasis, little is known about the hepatic impacts of exposure to environmentally relevant doses of BPA. Here we evaluated the effects of oral exposure to $50 \mu \mathrm{g} / \mathrm{kg} /$ day (TDI) or $5,000 \mu \mathrm{g} / \mathrm{kg} / \mathrm{day}$ (NOAEL) of BPA on mouse liver transcriptome. Initial genomewide microarray screenings evidenced a predominant impact of low BPA doses on lipid biosynthesis pathways. Using a wide range of doses, we showed that these effects are specific to low, environmentally relevant doses of BPA and correlate with an increased hepatic accumulation of neutral lipids.

\section{Materials and Methods}

Animals and Treatments. Six-week-old male CD1 mice (Charles River, Les Oncins, France) divided into five groups ( $n=6 /$ group) were administered BPA by way of the diet for 28 days (housing at $22 \pm 2^{\circ} \mathrm{C}$, 12-hour light/dark). A standard diet (ingredients from SAFE Diet, Augy, France) was formulated from maize starch (49\%), saccharose (24.4\%), casein (14\%), minerals $\operatorname{mix}(5 \%)$, peanut oil $(2.5 \%)$, rapeseed oil $(2.5 \%)$, cellulose $(2 \%)$, vitamins $\operatorname{mix}(0.5 \%)$, and methionine $(0.1 \%)$. BPA (4,4'-dihydroxy-2,2-diphenylpropane, CAS\# 80-05-7, Sigma-Aldrich, France) was incorporated in the diet at 0 (controls), 0.05, 0.5, 5, or $50 \mathrm{ppm}$. Considering a diet consumption of $10 \%$ of the body weight per day, this corresponds to an oral exposure of 0 (controls), 5, 50 (TDI), 500, or $5,000 \mu \mathrm{g}$ of $\mathrm{BPA} / \mathrm{kg} \mathrm{BW} /$ day (NOAEL), respectively. In vivo studies were conducted under E.U. guidelines for the use and care of laboratory animals and were approved by an independent ethics committee.

Blood and Organ Sampling. Blood was collected at the submandibular vein in heparin-coated capillaries. Plasma was prepared by centrifugation $(2,000 \mathrm{~g}$, 10 minutes) and kept at $-80^{\circ} \mathrm{C}$ until use. Following euthanasia, the liver and the perigonadic white adipose tissue (pWAT) were removed, weighed, dissected, snap-frozen in liquid nitrogen, and stored at $-80^{\circ} \mathrm{C}$ until use. Sampling was performed on two consecutive days ( $\mathrm{n}=3$ mice/group per day) but no block effect was statistically evidenced.

Gene Expression Studies. Total RNA was extracted with TRIzol reagent (Invitrogen, Cergy Pontoise, France). Transcriptomic profiles were obtained using 
Agilent Whole Mouse Genome microarrays $(4 \times 44 \mathrm{k})$ following the manufacturer's instructions. Microarray data and all experimental details are available in the Gene Expression Omnibus (GEO) database (accession GSE26728). For real-time quantitative polymerase chain reaction (qPCR), total RNA samples $(2 \mu \mathrm{g})$ were reverse-transcribed using the High Capacity cDNA Reverse Transcription Kit (Applied Biosystems, Courtaboeuf, France). Primers for SYBR Green assays are presented in Supporting Table 1. Amplifications were performed on an ABI Prism 7300 Real Time PCR System (Applied Biosystems). qPCR data were normalized by TATA-box binding protein (TBP) messenger RNA (mRNA) levels and analyzed with LinRegPCR. ${ }^{22}$

Immunoblot Analysis. Protein extracts were prepared using the Proteo-Jet cytoplasmic and nuclear extraction kit (Fermentas, Saint-Rémy-lès-Chevreuses, France). Following separation by sodium dodecyl sulfate-polyacrylamide gel electrophoresis (SDS-PAGE), liver proteins were probed with primary antibodies from Cell Signaling ( $\beta$-actin: 4970; lamin A/C: 2032; ACLY: 4332; ACLY-P: 4331; ACC: 3662; FAS: 3189), Abcam (estrogen receptor [ER]: ab16460; GK: ab37796), Santa Cruz Biotechnology (LXR: sc-13068; SCD1: sc-14719), Lab Vision (SREBP-1c: MS-1207P1ABX), Novus Biological (CHREBP: nb400-135), and secondary antibodies from Biotium (CF680 or CF770-labeled). G6PASE antibody was a gift from Dr. Gilles Mithieux. ${ }^{23}$ The images were analyzed on the Odyssey Infrared Imaging system (Li-Cor, Lincoln, $\mathrm{NE}$ ). Band intensities were normalized to those of $\beta$-actin or lamin A/C.

Biochemical Assays. Hepatic lipid content and FA composition were determined as described. ${ }^{24}$ Plasma levels of triglycerides, glucose, total cholesterol, low- or high-density lipoprotein (LDL, HDL) cholesterol were determined on a biochemical analyzer, COBASMIRA+. Plasma insulin was assayed with the ultrasensitive mouse insulin enzyme-linked immunosorbent assay (ELISA) kit (Crystal Chem, Downers Grove, IL).

Histology. Frozen liver samples were embedded in Neg 50 (Fisher Scientific, Courtaboeuf, France). Sections $(5 \mu \mathrm{m}$, Leica RM2145 microtome, Nanterre, France) were stained with Oil-Red-O and hematoxylin/eosin and visualized with a Leica DFC300 camera (Leica).

Statistical Analysis. All data were analyzed using R (www.r-project.org). Microarray data were processed with Bioconductor packages (www.bioconductor.org) as described in GEO entry GSE26728. Genes with q-value $\leq 0.1$ were considered differentially expressed between BPA-treated and control animals. The enrichment of Gene Ontology (GO) Biological Processes was evaluated using a conditional hypergeometric test (GOstats package). For data other than microarray data, differential effects were analyzed by analysis of variance (ANOVA) followed by Student's $t$ tests with a pooled variance estimate. $P \leq 0.05$ was considered significant.

\section{Results}

Low BPA Doses Increase Plasma Insulin. Male CD1 mice were exposed for 4 weeks to $0,5,50,500$, or $5,000 \mu \mathrm{g} / \mathrm{kg} /$ day of BPA by way of the diet. BPA exposure had no effect on body weight gain and relative liver weight (Fig. 1A). However, a significant increase in pWAT weight was observed in the animals exposed to $50 \mu \mathrm{g} / \mathrm{kg} / \mathrm{day}$ (Fig. 1A). Plasma insulin levels were significantly increased following exposure to 5, 50, and $500 \mu \mathrm{g} \mathrm{BPA} / \mathrm{kg} /$ day (Fig. 1B) with a maximal effect at the lowest dose. BPA had no significant effect on plasma glucose and total, LDL- or HDL-cholesterol levels. The animals exposed to $500 \mu \mathrm{g} \mathrm{BPA} / \mathrm{kg} /$ day displayed a significant increase in plasma triglyceride levels (Fig. 1B). To evaluate whether these observations were specific to a mouse strain and of a mode of BPA exposure, we performed an experiment in C57BL/6J mice exposed to the same BPA doses by way of the water. Although the modulations were generally of lower amplitude than in CD1 mice, the results obtained in this independent experiment were consistent with those presented here (Supporting Fig. 1).

Effects of BPA Reference Doses on Liver Transcriptome. Using microarrays, we compared the transcriptome of liver samples from mice exposed to BPA reference doses (TDI: $50 \mu \mathrm{g} / \mathrm{kg} / \mathrm{day}$ and NOAEL: $5,000 \mu \mathrm{g} / \mathrm{kg} /$ day) to those from control animals. The global impact of BPA-TDI or BPA-NOAEL is illustrated by the distribution of raw $P$-values for gene expression changes between BPA-treated groups and the control group (Fig. 2A). The overabundance of low $P$-values reflects the amplitude of the impact on the transcriptome. Exposure to BPA-TDI (174 unique genes differentially expressed compared with controls: 108 upregulated and 66 down-regulated; Supporting Table 2) had a stronger impact on liver transcriptome compared with BPA-NOAEL (0 genes with q-value $\leq 10 \%)$. A heatmap of the average intensities for the corresponding 196 unique oligonucleotide probes illustrates the specific impact of BPA-TDI on the expression of these genes compared with BPA-NOAEL. Among the up-regulated genes the nine GO categories 
A

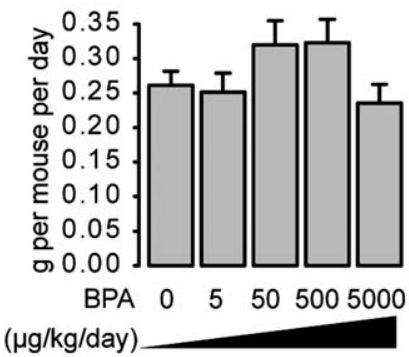

B
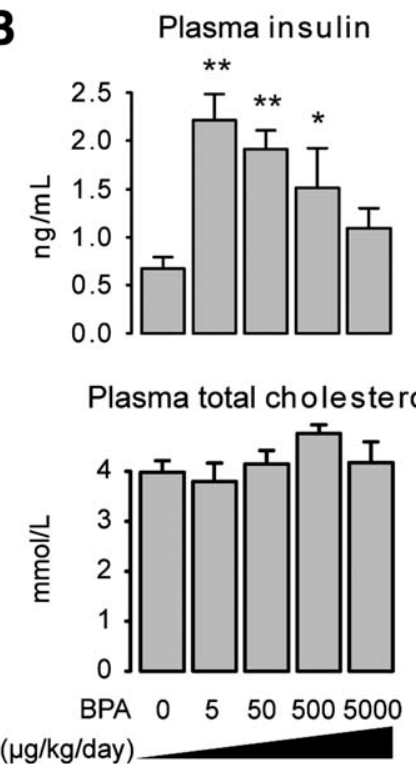

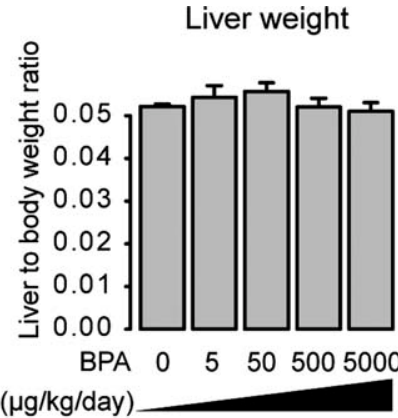

Plasma glucose

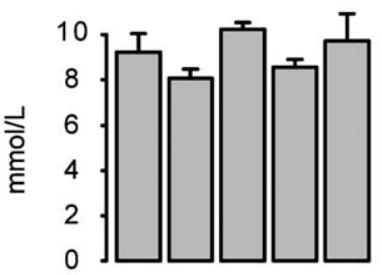

Plasma HDL-cholesterol

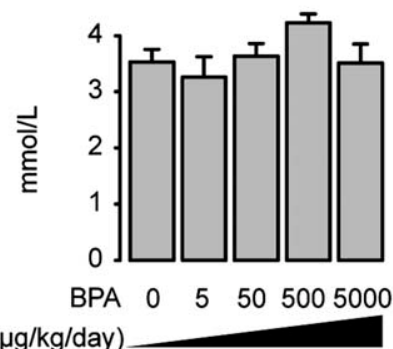

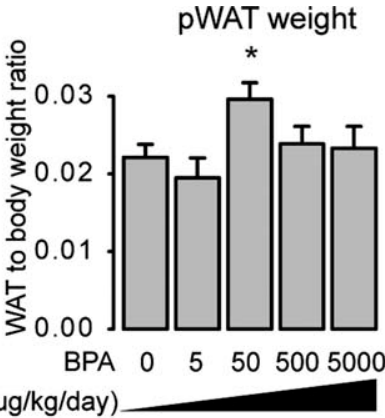

Plasma triglycerides

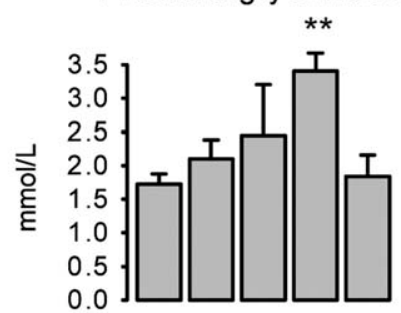

Plasma LDL-cholesterol

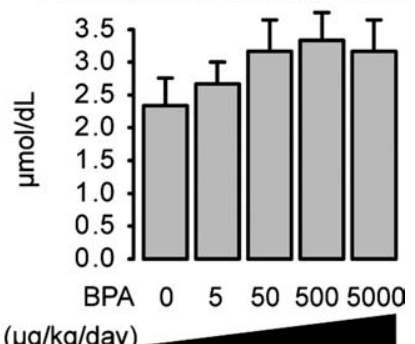

Fig. 1. Effects of different doses of BPA on body weight gain, on liver and adipose tissue weight, and on plasma parameters. (A) Body weight gain, liver weight (relative to body weight), and perigonadic white adipose tissue (pWAT) weight (relative to body weight) of male CD1 mice exposed orally for 28 days to different BPA doses $(0,5,50,500$, and $5,000 \mu \mathrm{g} / \mathrm{kg} /$ day, $\mathrm{n}=6$ animals/group). (B) Quantification of plasma insulin, glucose, triglycerides, cholesterol (total, HDL, LDL) from the same animals.

significantly overrepresented (q-value $\leq 10 \%$ ) were all related to lipid biosynthesis (Fig. 2B). Consistently, genes with increased expression at BPA-TDI included genes involved in de novo fatty acid (FA) synthesis (Acly: ATP citrate lyase, Acaca: Acetyl-CoA carboxylase alpha, Acacb: Acetyl-CoA carboxylase beta, Fasn) and elongation (Elovl6: long-chain FA elongase 6), in triglyceride synthesis (Gpat: glycerol-3-phosphate acyltransferase) and cholesterol synthesis (Mvd: mevalonate (diphospho) decarboxylase, Lss: lanosterol synthase). The most strongly induced gene at BPA-TDI was Pnpla3 (patatin-like phospholipase domain containing 3), a gene whose function is still poorly understood but whose genetic variability has been associated with the severity of nonalcoholic steatohepatitis (NASH). ${ }^{25}$ Another member of this family, Pnpla5 (patatin-like phospholipase domain containing 5) was also induced at the TDI. The Thrsp-Spot14 (thyroid hormone responsive Spot14 homolog) is the second most strongly induced gene at BPA-TDI versus control. Its overexpression was previously shown to increase lipogenesis in human hepatocytes. ${ }^{26}$ To identify enriched functional categories among the regulated genes independently of the q-value/FDR threshold, we used gene set enrichment analysis (GSEA, data not shown). Results of GSEA for the up-regulated genes also pointed to increased lipogenesis as the main and specific impact of BPA-TDI. Interestingly, GSEA identified an enrichment of peroxisome proliferator-activated receptor alpha (PPAR $\alpha)$ target genes involved in FA oxidation among the down-regulated genes for both BPA reference doses.

\section{Low BPA Doses Induce Hepatic Gene Expression} Related to Lipid Biosynthesis. Based on microarray results, we evaluated by $\mathrm{qPCR}$ the effects of a wide range of BPA doses $(0,5,50,500$, and $5,000 \mu \mathrm{g} / \mathrm{kg} /$ day) on the expression of genes related to hepatic lipid metabolism. Figure 3 illustrates that the effects of BPA 
A

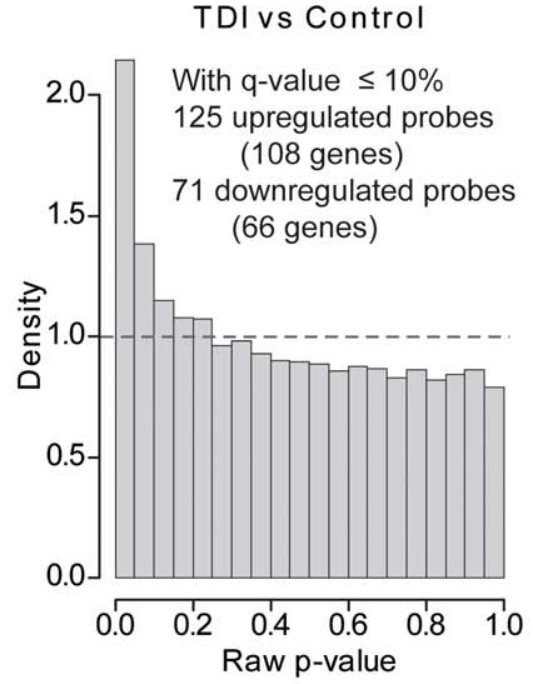

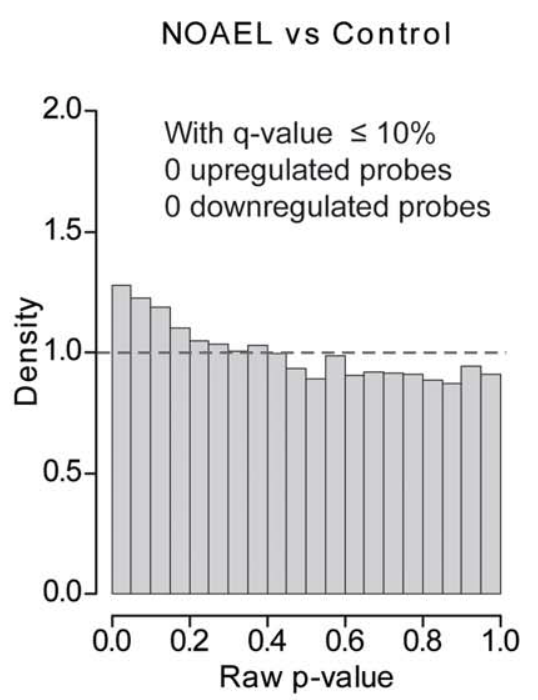

NOAEL vs Control

B

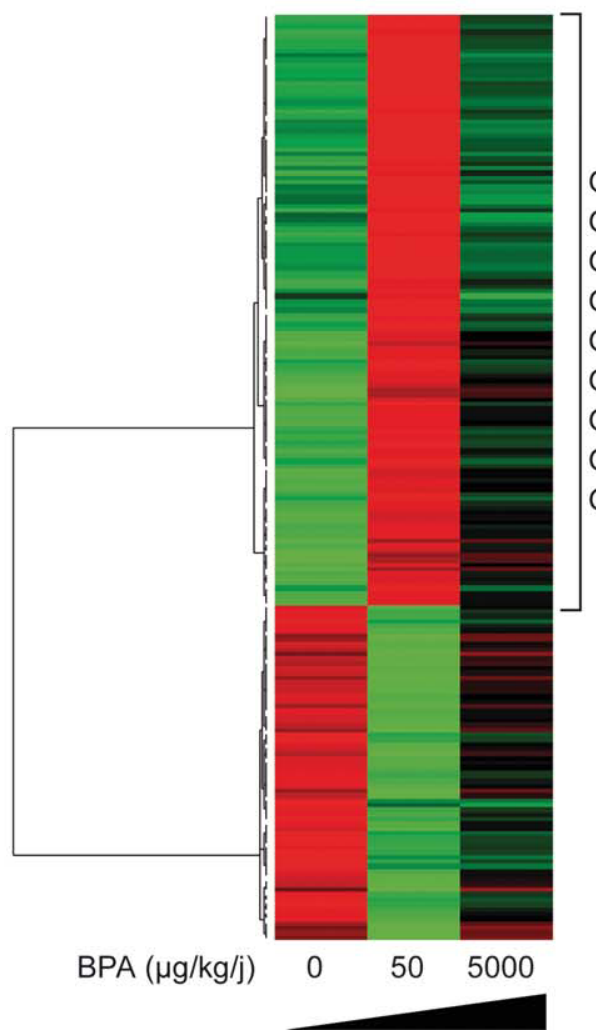

Over-represented GO functions (q-value $<0.1$ ) GO:0016053: organic acid biosynthetic process GO:0032787: monocarboxylic acid metabolic process GO:0044255: cellular lipid metabolic process GO:0006695: cholesterol biosynthetic process GO:0006633: fatty acid biosynthetic process GO:0016125: sterol metabolic process GO:0043436: oxoacid metabolic process GO:0006694: steroid biosynthetic process GO:0006629 : lipid metabolic process

Fig. 2. Effects of BPA reference doses on liver transcriptome. mRNAs were extracted from the livers of male CD1 mice $(\mathrm{n}=6 /$ group) exposed or not to a low (TDI: $50 \mu \mathrm{g} / \mathrm{kg} /$ day) or high dose (NOAEL: $5,000 \mu \mathrm{g} / \mathrm{kg} /$ day) of BPA. Hepatic transcriptomes were analyzed using Agilent Whole Mouse Genome microarrays $(4 \times 44 \mathrm{~K})$. (A) Distribution of raw $P$-values corresponding to the comparison between BPA-treated and control group. The dashed lines illustrate the flat histogram that is expected in the absence of BPA effect. The overabundance of low $P$-values (peak on the left of the histogram) illustrates graphically the global impact of the treatments on the transcriptome. The number of significant (q-value $\leq 10 \%)$ upand down-regulated probes and of the corresponding number of genes are indicated. (B) The heatmap for the 196 probes significantly regulated at BPA-TDI versus control illustrates the specific impact of the low dose $(50 \mu \mathrm{g} / \mathrm{kg} /$ day $)$ compared with the high dose $(5,000 \mu \mathrm{g} / \mathrm{kg} / \mathrm{day})$. Red and green colors indicate values above and below the mean, respectively. Black color indicates values close to the mean. Only the mean values for each group are represented in the heatmap but the hierarchical clustering was obtained from individual values using 1-Pearson correlation coefficient as distance and the Ward's criterion for agglomeration. Analysis of G0 biological functions significantly enriched (q-value $\leq 10 \%$ ) among the up-regulated genes clearly pointed to processes linked to lipid metabolism as the most robustly enriched.

on key enzymes involved in lipogenesis (Fig. 3A), cholesterol biosynthesis (Fig. 3B), and to a lesser extent in glucose metabolism (Fig. 3C) follow a nonmonotonic dose-response relationship. Key microarray findings were confirmed for Acly, Acaca, Acacb, Elovl6, Fasn, Thrsp-Spot14 (Fig. 3A), Mvd, Lss (Fig. 3B), Gpat, 
A
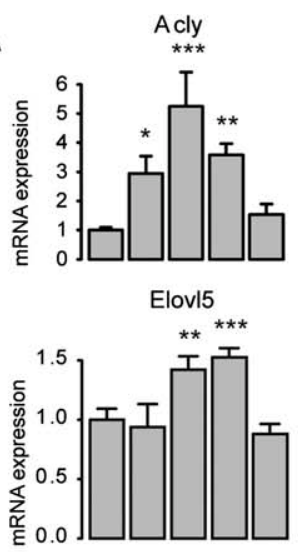

Lpin 1

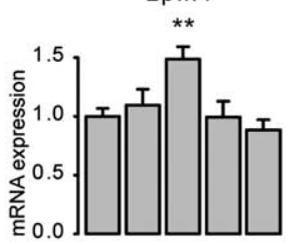

BPA $0 \quad 5 \quad 505005000$ $(\mu \mathrm{g} / \mathrm{kg} / \mathrm{day})$

B
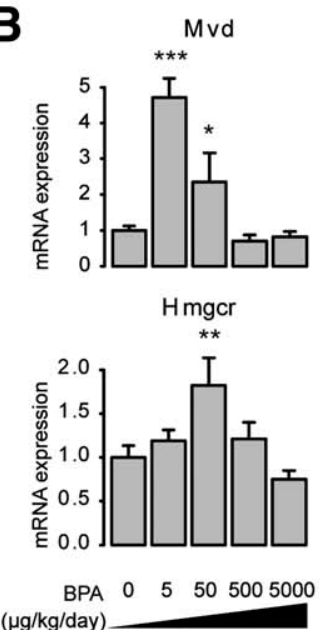

D

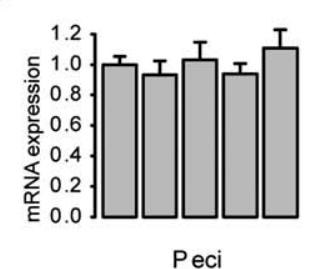

Peci

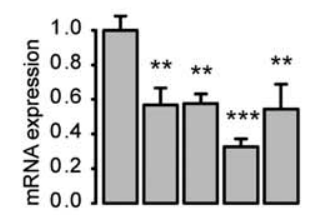

BPA $0 \quad 5 \quad 505005000$

$(\mu \mathrm{g} / \mathrm{kg} / \mathrm{day})$
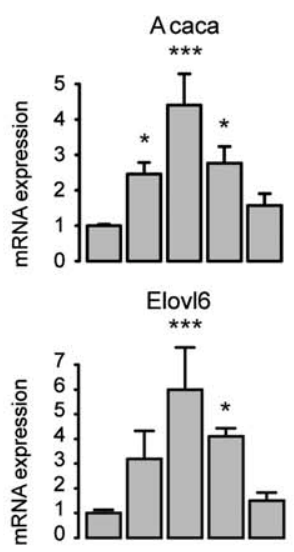

Thrsp-Spot14

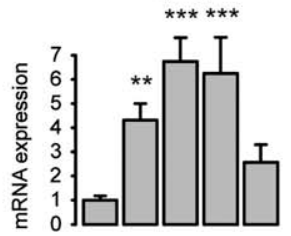

BPA $0 \quad 5 \quad 505005000$ ( $\mu \mathrm{g} / \mathrm{kg} /$ day $)$
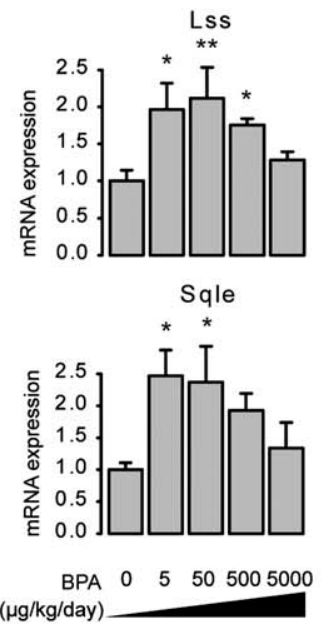

Cpt1a

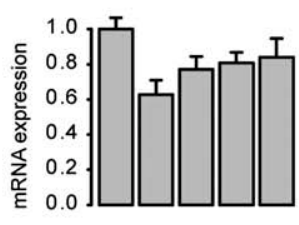

Cyp4a14

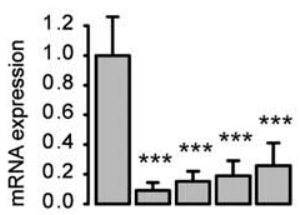

BPA $0 \quad 5 \quad 505005000$ $(\mu \mathrm{g} / \mathrm{kg} / \mathrm{day})$
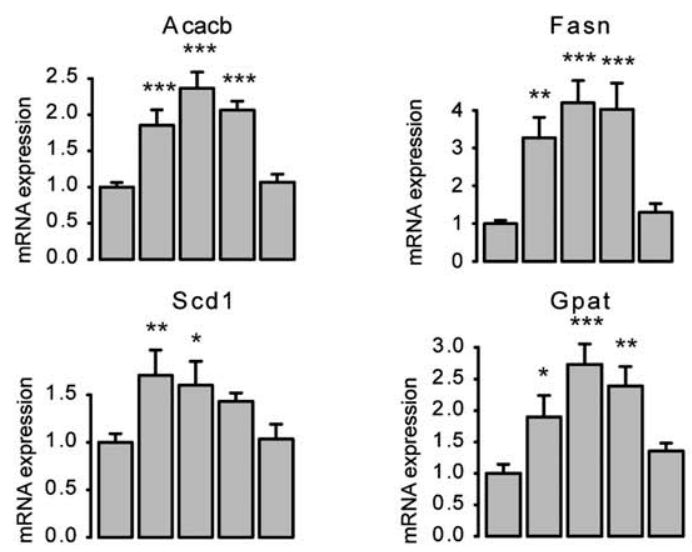

$$
\text { Pnpla3 }
$$

Pnpla5

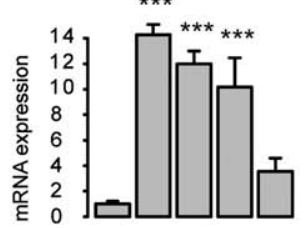

BPA 05505005000 $(\mu \mathrm{g} / \mathrm{kg} / \mathrm{day})$
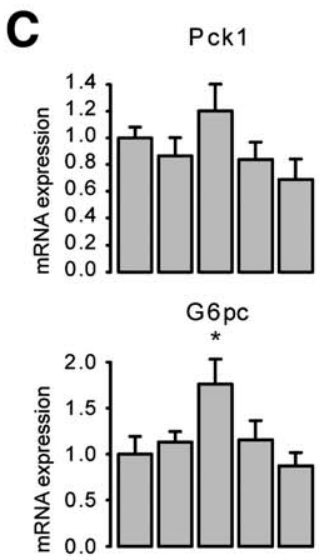

BPA $0 \quad 5 \quad 505005000$ $(\mu \mathrm{g} / \mathrm{kg} / \mathrm{day})$

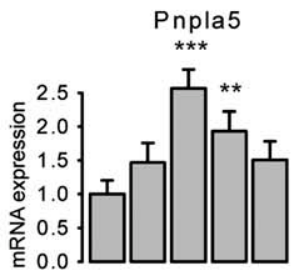

BPA $0 \quad 5 \quad 505005000$ $(\mu \mathrm{g} / \mathrm{kg} / \mathrm{day})$

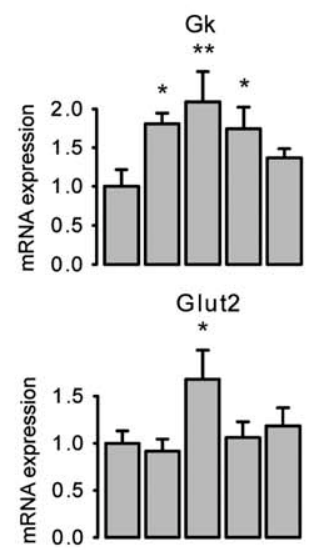

BPA $0 \quad 5 \quad 505005000$ $(\mu \mathrm{g} / \mathrm{kg} / \mathrm{day})$

E

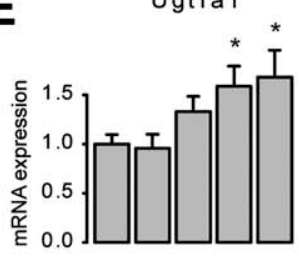

BPA $0 \quad 5 \quad 505005000$ $(\mu \mathrm{g} / \mathrm{kg} / \mathrm{day})$

Fig. 3. 
Pnpla3, and Pnpla5 genes (Fig. 3A). Similar patterns of expression were also observed for Elovl5 (FA elongation), Scd1 (synthesis of monounsaturated FA), Lpin1 (triglyceride synthesis, Fig. 3A), Hmgcr, and Sqle (cholesterol biosynthesis, Fig. 3B). Because hepatic glucose and lipid metabolism are tightly linked, we analyzed the expression of genes involved in glucose homeostasis. A similar effect of BPA was observed for both the phosphoenolpyruvate carboxykinase 1 (Pck1) and the glucose-6-phosphatase (G6pc), which are involved in gluconeogenesis (Fig. 3C). The mRNA expression of glucokinase (Gk) which regulates glycolysis was also increased (Fig. $3 \mathrm{C}$ ). An induction of the main hepatic glucose transporter (Glut2) was also observed (Fig. 3C). These effects on glucose metabolism-related genes were almost exclusively significant at BPA-TDI and were of more modest amplitude compared with those affecting genes involved in lipid metabolism.

Based on GSEA results, we evaluated the effects of BPA exposure on the expression of genes involved in FA oxidation. BPA had no effect on the expression of Acox1 or Cpt1a involved in peroxisomal and mitochondrial $\beta$-oxidation, respectively (Fig. 3D). However, all BPA doses reduced the expression of Peci involved in the metabolism of unsaturated FA and of Cyp4a14, two target genes of PPAR $\alpha$ (Fig. 3D).

We also studied the impact of BPA on the mRNA expression of genes involved in FA uptake and very low-density lipoprotein (VLDL) secretion. The results obtained did not suggest an upregulation of these pathways at low BPA doses (Supporting Fig. 2).

Finally, we searched for a more classical monotonic dose-response relationship between BPA exposure and gene expression. This led us to show that the expression of UDP glucuronyltransferase 1a1 (Ugt1a1), an enzyme involved in the phase II metabolism of xenobiotics and hormones, including estradiol is dosedependently increased by BPA (Fig. 3E).
Western blot analysis for key lipogenic proteins (ACLY and its more active form phosphorylated on Ser454: ACLY-P, ACC, FAS, and SCD1), for GK, and for G6PASE showed protein levels consistent with the mRNA changes (Fig. 4).

Effects of BPA on Hepatic Transcription Factors. In order to gain insight into the transcriptional mechanisms which could contribute to the effects of BPA on liver gene expression, we measured the expression of different transcription factors involved in the regulation of hepatic energy metabolism. These included several nuclear receptors: PPAR $\alpha$; the adipogenic regulator $\operatorname{PPAR} \gamma ; \operatorname{PPAR} \beta / \delta$; liver X receptor alpha $(\mathrm{LXR} \alpha)$; $\mathrm{ER} \alpha$; constitutive androstane receptor (CAR); pregnane $\mathrm{X}$ receptor (PXR), and the hepatocyte nuclear factor $4 \alpha(\mathrm{HNF} 4 \alpha)$. BPA had no significant effect on the expression of $\mathrm{Pxr}$ and $\mathrm{Hnf} 4 \alpha$ (Fig. 5A). The expression of Car was highest in control mice and was significantly reduced in mice exposed to 5 and $50 \mu \mathrm{g}$ BPA $/ \mathrm{kg} /$ day (Fig. 5A). On the opposite, ER $\alpha$ expression was lowest in control mice and was significantly increased in mice exposed to 5 and $50 \mu \mathrm{g} / \mathrm{kg} / \mathrm{day}$ (Fig. $5 \mathrm{~A})$. We did not detect the expression of $\mathrm{ER} \beta$ in liver samples. Ppar $\alpha$ expression was decreased almost 3-fold in mice exposed to 5 or $500 \mu \mathrm{g} \mathrm{BPA} / \mathrm{kg} /$ day only (Fig. $5 A) . P \operatorname{par} \beta / \delta$ expression was significantly increased by about $50 \%$ in mice exposed to $500 \mu \mathrm{g}$ BPA $/ \mathrm{kg} / \mathrm{day}$ but a trend toward increased expression was also observed at 5 and $50 \mu \mathrm{g} / \mathrm{kg} /$ day (Fig. 5A). Ppar $\gamma$ and Lxr $\alpha$ expression were clearly increased by 4 - and 2 fold, respectively, in the liver of mice exposed to BPATDI only (Fig. 5A). We also measured the expression of sterol regulatory element binding protein $1 \mathrm{c}$ (SREBP-1C), a major regulator of de novo lipogenesis, $^{27}$ of sterol regulatory element binding protein 2 (SREBP-2), which regulates cholesterol metabolism, ${ }^{28}$ and of carbohydrate response element binding protein (ChREBP), a transcriptional regulator of glucose and lipid metabolism. ${ }^{29}$ The expression of Srebp-1c,

Fig. 3. Effects of BPA exposure on hepatic gene expression related to lipogenesis, cholesterol biosynthesis, glucose metabolism, and fatty acid oxidation. Hepatic mRNAs from male CD1 mice exposed to different doses of BPA $(0,5,50,500$, and $5,000 \mu g / k g / d a y)$ were used to assay by qPCR the relative expression of genes involved in (A) lipogenesis (Acly: ATP citrate lyase, Acaca: acetyl-CoAcarboxylase alpha, Acacb: acetyl-CoAcarboxylase beta, Fasn: fatty acid synthase, Elovl5 and Elovl6: elongation of long chain fatty acids family members 5 and 6 , Scd1: stearoyl-CoA desaturase-1, Gpat: glycerol-3-phosphate acyltransferase, Lpin1: Lipin 1, Thrsp-Spot14: thyroid hormone responsive Spot14 homolog, Pnpla3 and Pnpla5: patatin-like phospholipase domain containing 3 and 5) (B) cholesterol biosynthesis (Mvd: mevalonate (diphospho) decarboxylase, Lss: lanosterolsynthase, Hmgcr: Hmg-coenzyme A reductase and Sqle: squalene epoxidase) (C) glucose metabolism (Pck1: phosphoenolpyruvate carboxykinase 1, Gk: glucokinase, G6pc: glucose-6-phosphatase, and Glut2: glucose transporter 2) (D) fatty acid oxidation (Acox1: acyl-coenzyme A oxidase 1, Cpt1a: carnitine palmitoyltransferase 1A, Peci: peroxisomal 3,2-trans-enoyl-CoA isomerase, Cyp4a14: cytochrome P450, family 4, subfamily a, polypeptide 14) (E) Ugt1a1: UDP-glucuronosyltransferase 1 polypeptide A1. All data were normalized to TBP (TATA-box binding protein) mRNA expression levels. Values shown are the mean \pm standard error of the mean (SEM) ( $\mathrm{n}=6$ per group). Data were analyzed by ANOVA followed by post-hoc Student's test with a pooled variance estimate. Asterisk denotes a significant difference compared with control condition $(0 \mu \mathrm{g} / \mathrm{kg} /$ day of $\mathrm{BPA})$ : $* P<0.05$; ${ }^{* *} P<0.01 ; * * * P<0.001$. 
A

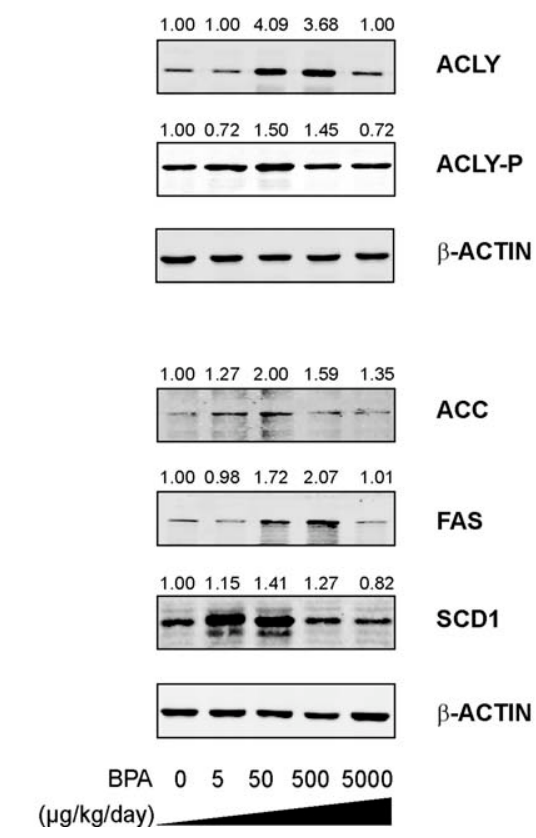

B

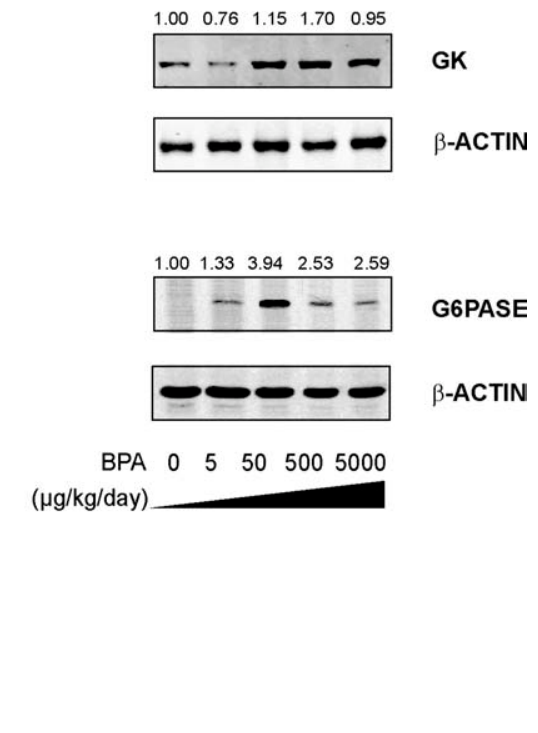

Fig. 4. Western blot analysis of the effect of BPA exposure on hepatic protein expression. Cytoplasmic protein extracts were prepared from the livers of control and BPA-exposed animals $(0,5,50,500$, and 5,000 $\mu \mathrm{g} / \mathrm{kg} /$ day; $\mathrm{n}=3$ to 6 animals/group). The protein extracts were subjected to SDS-PAGE and transferred on nitrocellulose membranes. Hepatic proteins were probed using antibodies specific to (A) key enzymes involved in fatty acid biosynthesis: ATP citrate lyase (ACLY), the more active form of ACLY phosphorylated on Ser454 (ACLY-P), acetyl-CoA carboxylase (ACC), fatty acid synthase (FAS), and stearoyl-CoA desaturase-1 (SCD1) and (B) key enzymes involved in glucose metabolism: glucokinase (GK) and glucose 6-phosphatase (G6PASE). $\beta$-Actin was used as loading control. A representative image is shown for each protein. The values indicated above each image are the mean values obtained for 3 to 6 animals per group.

Srebp-2, and Chrebp exhibited an inverted U-shaped dose-response profile under the effect of BPA (Fig. $5 \mathrm{~B})$. This was also the case for insulin induced gene 1 (Insig1), but not for insulin induced gene 2 (Insig2), two negative regulators of SREBP-2 and SREBP-1c processing, respectively (Fig. 5B). The analysis by western blot of nuclear protein levels for ER and for the key regulators of lipogenesis SREBP-1C, CHREBP and LXR confirmed a specific effect of low BPA doses on the active protein levels of these transcription factors (Fig. 5C).

Effects of BPA on Hepatic Lipids and FA Composition. To evaluate the consequences of increased expression of lipogenic genes, we stained hepatic neutral lipids with Oil-Red-O. The representative pictures in Fig. 6A illustrate a greater accumulation of lipids in the liver of mice exposed to BPA compared with control livers. Lipid droplets were larger and more numerous in the livers of mice exposed to BPA-TDI compared with those exposed to BPA-NOAEL. The quantification of liver lipid content confirmed these observations. BPA had no effect on hepatic total free cholesterol content (not shown). Liver triglycerides were significantly increased by approximately $60 \%$ and $65 \%$ in mice exposed to 50 and $500 \mu \mathrm{g} \mathrm{BPA} / \mathrm{kg} / \mathrm{day}$, respectively, compared with control mice (Fig. 6B). Additionally, mice exposed to BPA-TDI also showed a significant increase in hepatic cholesteryl esters (Fig. 6B). The analysis of hepatic FA composition (Fig. 6C; Supporting Table 3) showed that exposure to 50 or $500 \mu \mathrm{g} \mathrm{BPA} / \mathrm{kg} /$ day resulted in accumulation of palmitic (C16:0) and oleic acids (C18:1n-9), the major constituents of triglycerides and cholesteryl esters. Conversely, the proportions of polyunsaturated FA and of C18:0, which are found at higher levels in phospholipids, were reduced at these doses. Despite increased Elov16 mRNA expression, the C18:0/C16:0 ratio was decreased at these doses. This may result from a combined increased synthesis of C16:0 by FAS and the efficient desaturation/elongation of C18:0 (as illustrated by the increased C18:1n-9/C18:0 ratio, Fig. 6D), both producing substrates for triglyceride synthesis.

\section{Discussion}

Our results show that the oral exposure of adult male mice to low BPA doses increases plasma insulin and hepatic mRNA and protein expression related to lipid biosynthesis. This correlates with increased liver lipids after 4 weeks of exposure. Most significant 

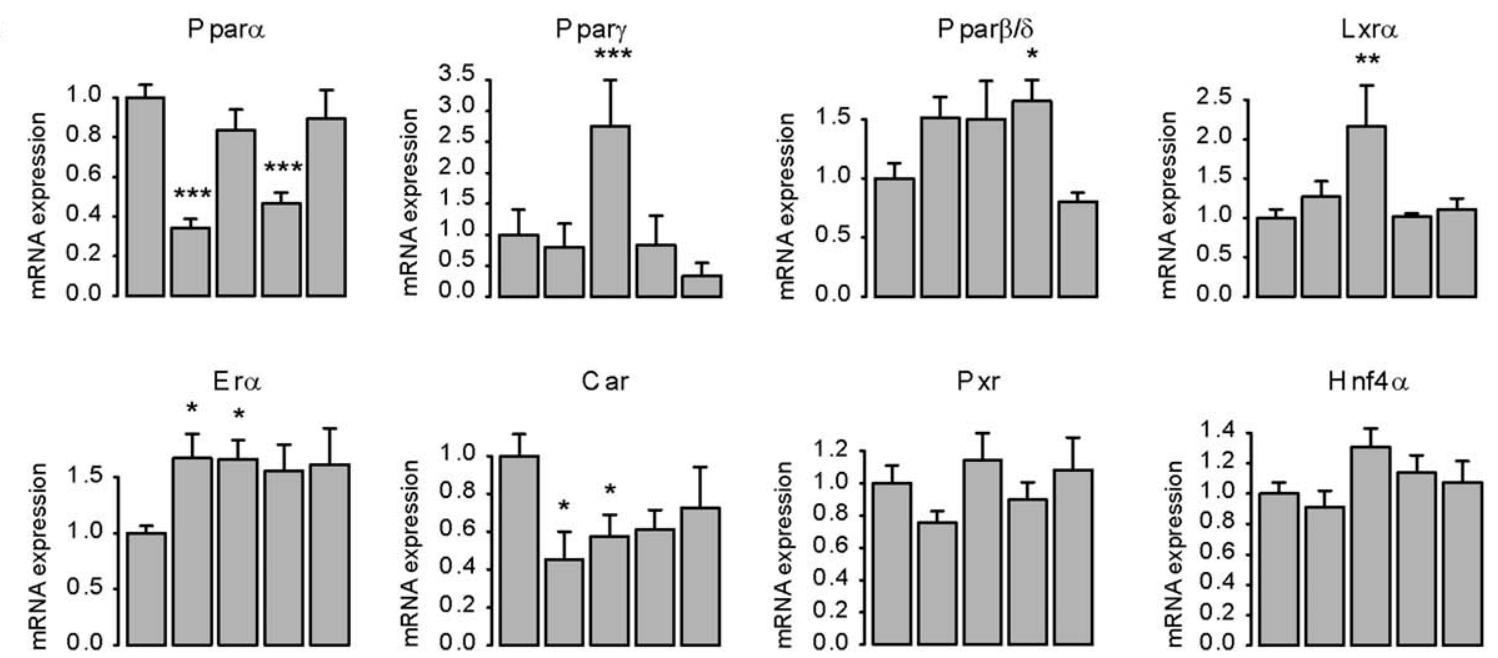

BPA $0 \quad 5 \quad 505005000$

BPA $0 \quad 5 \quad 505005000$

BPA $0 \quad 5 \quad 505005000$ $(\mu \mathrm{g} / \mathrm{kg} /$ day $)$ $(\mu \mathrm{g} / \mathrm{kg} / \mathrm{day})$

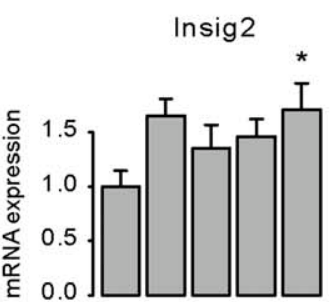

C
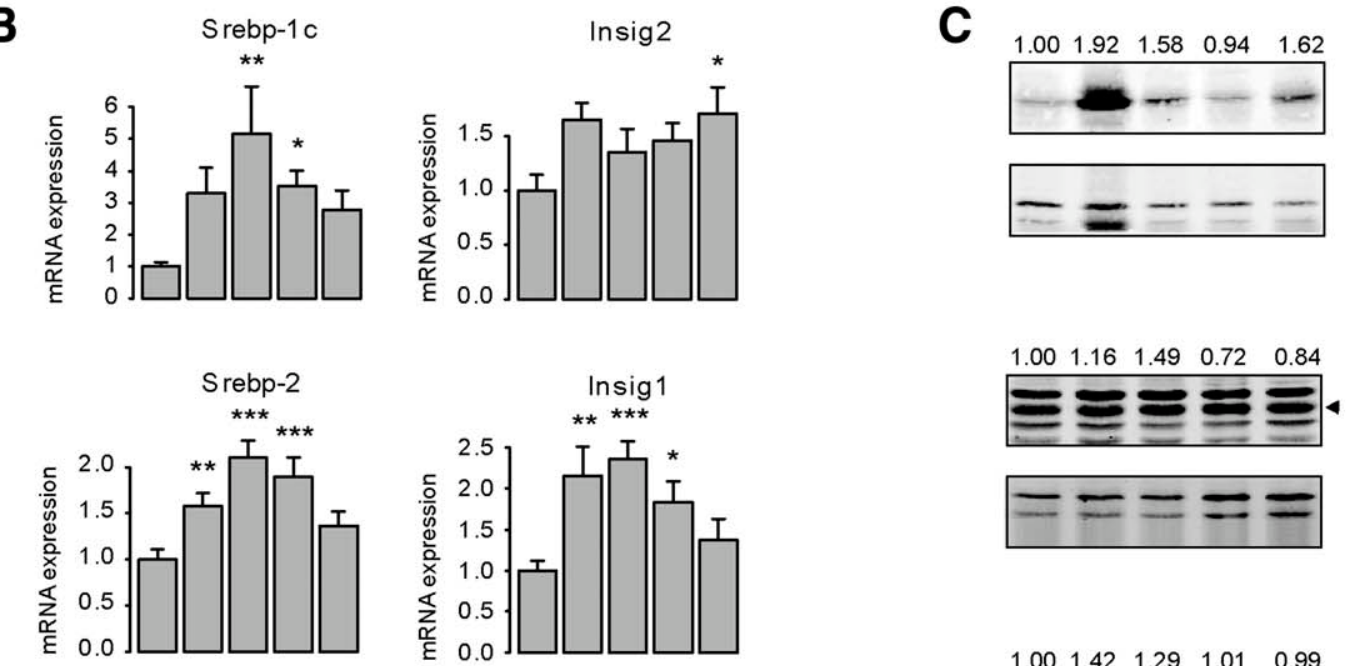

LXR

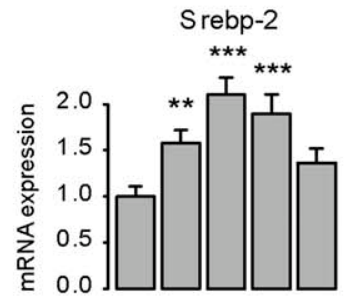

BPA $0 \quad 5 \quad 505005000$

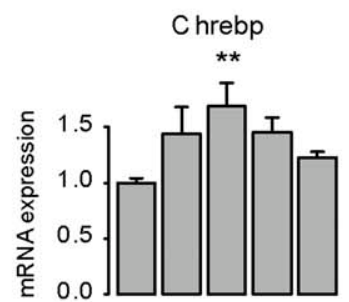

$(\mu \mathrm{g} / \mathrm{kg} / \mathrm{day})$

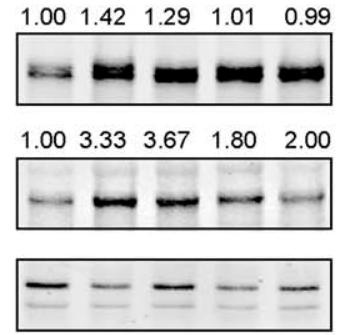

\section{CHREBP}

SREBP-1C

BPA $\quad 0 \quad 5 \quad 50 \quad 5005000$

BPA 05505005000 $(\mu \mathrm{g} / \mathrm{kg} / \mathrm{day})$

Fig. 5. Effects of low BPA doses on the expression of master transcriptional regulators of hepatic lipid and glucose homeostasis. Hepatic mRNAs from male CD1 mice exposed to different doses of BPA $(0,5,50,500$, and $5,000 \mu \mathrm{g} / \mathrm{kg} /$ day) were used to assay by qPCR the relative mRNA expression of (A) nuclear receptors: the peroxisome proliferator-activated receptors alpha (Ppar $\alpha)$, gamma $($ Ppar $\gamma)$, beta/delta $(P p a r \beta / \delta)$, the liver $X$ receptor alpha $(\mathrm{Lx} \alpha)$, the estrogen receptor alpha $(E R \alpha)$, the constitutive androstane receptor (Car), the pregnane $X$ receptor (Pxr), and the hepatocyte nuclear factor $4 \alpha(\mathrm{Hnf} 4 \alpha)(\mathrm{B})$ and of other transcriptional regulators of hepatic lipid and glucose metabolism: the sterol regulatory element binding transcription factor $1 \mathrm{c}$ (Srebp-1c) and its associated factor encoded by the Insulin induced gene (Insig2), the sterol regulatory element binding transcription factor 2 (Srebp-2) and its associated factor encoded by the insulin induced gene 1 (Insig1), and the carbohydrate response element binding protein (Chrebp). All data were normalized to TBP (TATA-box binding protein) mRNA expression levels. Values shown are the mean \pm SEM ( $n=6$ per group). Data were analyzed by ANOVA followed by post-hoc Student's test with a pooled variance estimate. Asterisk denotes a significant difference compared with control condition $(0 \mu \mathrm{g} / \mathrm{kg} / \mathrm{day}$ of $\mathrm{BPA})$ : ${ }^{*} P<0.05 ; * * P<0.01$; $* * * P<0.001$. (C) Immunoblots for ER, LXR, CHREBP, and SREBP-1C were performed as described in the legend of Fig. 4 except that nuclear proteins were extracted and analyzed and that LAMIN A/C was used as a loading control. The values indicated are the mean of the values obtained for 3 animals per group. 
A
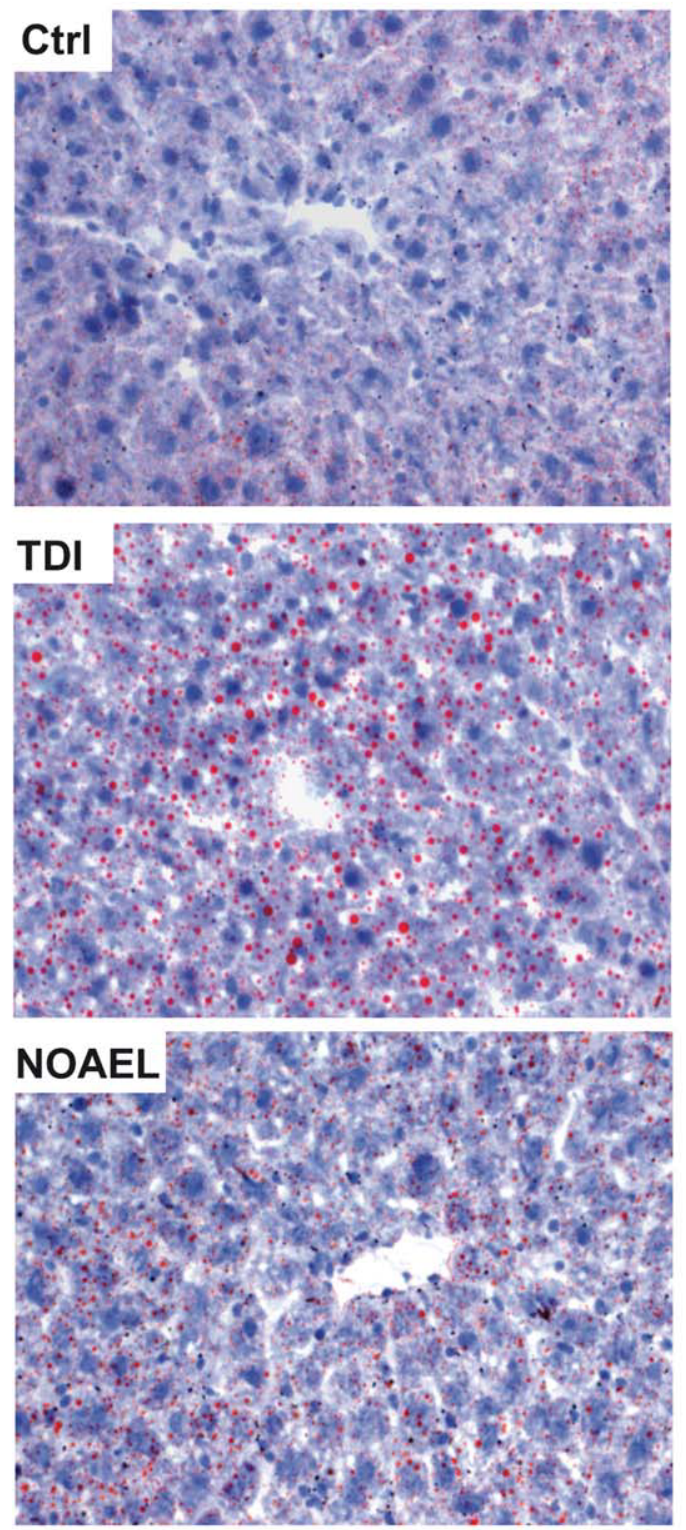

B

Hepatic cholesteryl esters

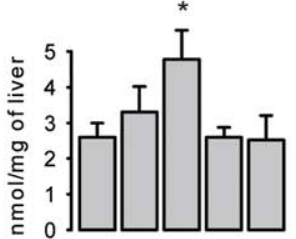

BPA $0 \quad 5 \quad 505005000$ $(\mu \mathrm{g} / \mathrm{kg} / \mathrm{day})$
Hepatic triglycerides

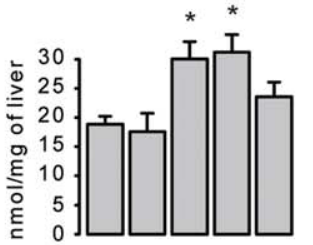

BPA $0 \quad 5 \quad 505005000$

$(\mu \mathrm{g} / \mathrm{kg} / \mathrm{day})$

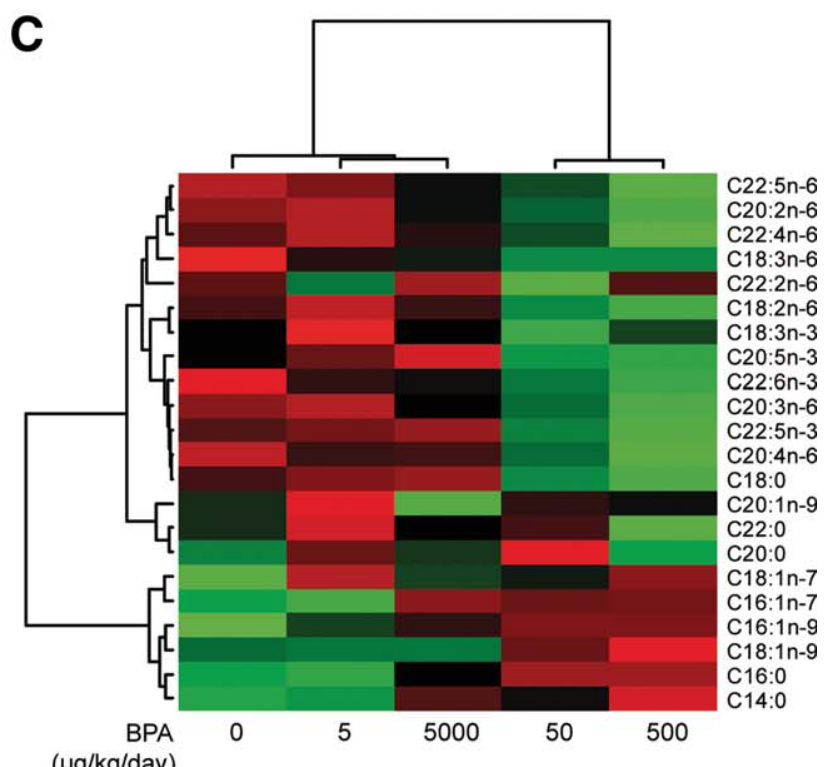

D

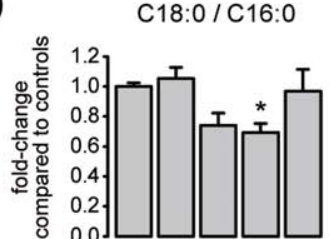

BPA $0 \quad 5 \quad 505005000$

$(\mu \mathrm{g} / \mathrm{kg} / \mathrm{day})$

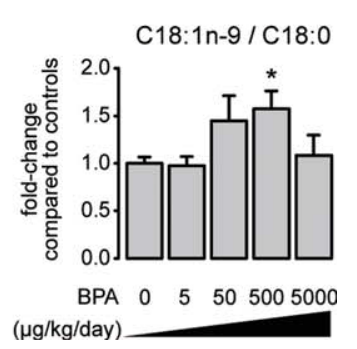

Fig. 6. Accumulation of triglycerides and cholesteryl esters and changes in the fatty acid profile in the livers of mice exposed to BPA low doses. (A) Oil-Red-0-staining of neutral lipids realized on histological sections of livers from mice exposed or not to a BPA low dose (TDI: 50 $\mu \mathrm{g} / \mathrm{kg} /$ day) or high dose (NOAEL: $5,000 \mu \mathrm{g} / \mathrm{kg} /$ day). Neutral lipids appear in red (original magnification $\times 200$ ). (B) Neutral lipids were extracted from the liver of mice exposed to different doses of BPA $(0,5,50,500$, and $5,000 \mu \mathrm{g} / \mathrm{kg} /$ day) by way of their diet. After extraction, lipids were analyzed by gas chromatography. The presence of internal standards enabled to quantify neutral lipids. Values shown are the mean \pm SEM ( $n=6$ per group). Data were analyzed by ANOVA followed by post-hoc Student's test with a pooled variance estimate. ${ }^{*} P<0.05:$ significant difference compared with control condition $(0 \mu \mathrm{g} / \mathrm{kg} /$ day of BPA). (C) The hepatic fatty acid composition of mice exposed to the five BPA doses ( $n=5$ or 6 per group) were determined by gas chromatography of fatty acid methyl esters. The heatmap and the dendrograms were obtained as described in the legend of Fig. 2. The clustering of the groups clearly identifies a specific impact of exposure to 50 and $500 \mu g$ $\mathrm{BPA} / \mathrm{kg} /$ day on the fatty acid profile. It is characterized by increased proportions of saturated and monounsaturated fatty acids and reduced proportions of polyunsaturated fatty acids and C18:0. (D) A significant decrease in the C18:0/C16:0 ratio and a concomitant increase in the C18:1n-9/C18:0 ratio are observed in the livers of animals exposed to $500 \mu \mathrm{g} \mathrm{BPA} / \mathrm{kg} /$ day.

effects were observed for BPA doses within one order of magnitude around the current TDI of $50 \mu \mathrm{g} / \mathrm{kg} / \mathrm{day}$. Conversely, virtually no effects were observed at the NOAEL $(5,000 \mu \mathrm{g} / \mathrm{kg} /$ day $)$. Agencies for risk assessment have established a "safe" TDI for BPA at $50 \mu \mathrm{g} /$ $\mathrm{kg} / \mathrm{day}$, but several studies have revealed that exposure to environmentally relevant BPA doses below the TDI alters various biological functions, including reproductive, behavioral, metabolic, and immune systems. ${ }^{4}$ However, the molecular mechanisms underlying these 
low-level responses are still unknown. It was proposed that down-regulation of receptors at higher hormone or xenoestrogen levels may contribute to shape these nonmonotonic curves. Some of BPA's actions, including insulin production by the pancreas, were attributed to its ability to bind to nonclassical membrane estrogen receptor as well as the G-protein coupled-receptor 30 (GPR30) and to act through nongenomic pathways. $^{20,30}$ Interestingly, we observed that, contrary to lipid metabolism genes, Ugt1a1 expression displayed a dose-dependent increase in response to BPA (Fig. 3E). Human UGT1a1 mRNA expression has been previously reported to be increased by low BPA doses in HepG2 cells. ${ }^{31}$ This phase II enzyme is involved in the metabolism of endogenous estrogens ${ }^{32}$ and has also been shown to catalyze BPA glucuronidation at high substrate concentration. ${ }^{33}$ Whether the modest increase in Ugtlal expression can interfere with the action of BPA and/or endogenous estrogens may be doubtful, but it suggests that different pathways with different sensitivities to BPA are targeted depending on the dose of exposure.

The effects of BPA on insulin expression and secretion have been described. ${ }^{17}$ Our results strongly suggest that the effects of BPA on insulin production by the pancreas translate to transcriptional and functional consequences in the liver. Indeed, insulin is known to increase glycolysis and lipogenesis by way of both posttranslational protein modifications and transcriptional mechanisms. ${ }^{34}$ SREBP-1c plays a major role in the regulation of these genes in response to insulin. ${ }^{35} \mathrm{LXR}$ is thought to contribute to the effect of insulin on Srebp-1c gene expression. ${ }^{36}$ LXR also directly regulates the expression of lipogenic genes. ${ }^{37}$ Additionally, insulin also stimulates the proteolytic processing of SREBP-1c, ${ }^{38}$ leading to increased mature nuclear form and subsequent induction of lipogenic gene expression. In addition to insulin, glucose stimulates glycolytic and lipogenic gene expression by activating the ChREBP, ${ }^{29}$ which is itself under the transcriptional control of LXR. ${ }^{39}$ Insulin also induces the expression of Spot14, which is required for induction of hepatic lipogenesis by thyroid hormone and insulin ${ }^{40,41}$ and of Pnpla3 by way of SREBP1-c. ${ }^{42}$ SREBP-2 expression and activity are primarily regulated by low sterol levels but were also reported to respond to increased insulin levels. ${ }^{43,44}$ SREBP-2 is a major transcriptional regulator of genes involved in cholesterol biosynthesis, including Hmgcr and Sqle. ${ }^{45}$ Thus, insulin is likely to contribute to a large number of the regulations observed following BPA exposure. However, although the expression of some genes (e.g., Pnpla3) parallels plasma insulin levels, many other gene expression patterns do not strictly follow the insulin profile. Moreover, the up-regulation of genes involved in neoglucogenesis (G6pc and Pck1, Fig. 3C) is unexpected in the context of high insulin levels. We cannot rule out that other mechanisms, independent of insulin and possibly involving direct effects of BPA on the liver, may contribute to the transcriptional impacts of low BPA doses reported here.

We have shown an accumulation of liver triglycerides and cholesteryl esters together with associated changes in hepatic FA composition in the animals exposed to low BPA doses. Among the mechanisms potentially involved in these effects (increased FA uptake, impaired secretion, increased lipogenesis, or reduced oxidation), our results point to an activation of lipogenesis and cholesterol biosynthesis as the major mechanism involved, potentially associated with an inhibition of FA oxidation. Simple hepatic lipid accumulation is generally considered a benign and reversible process that does not invariably progress to a more serious condition. However, inappropriate regulation of hepatic de novo lipogenesis is now believed to facilitate the generation of lipotoxic lipid intermediates that could contribute to the pathogenesis of NASH. ${ }^{46}$ NAFLD is strongly linked to overnutrition, underactivity, and insulin resistance, ${ }^{47}$ but many other factors initiating hepatic steatosis or supporting the progression of NAFLD to NASH have been proposed. ${ }^{48}$ These include biologic or synthetic hepatotoxins, bacterial endotoxins, and exposure to industrial petrochemicals. Because hepatic steatosis may lead to more severe pathologies such as NASH and fibrosis, the effects of environmental pollutants on liver functions should be carefully examined.

Acknowledgment: We thank Colette Bétoulières, Raymond Gazel and Florence Blas Y Estrada for animal care and technical assistance for animal experiments and Joëlle Laffitte for help in setting up protein analyses. We thank Dr. Gilles Mithieux (INSERM U855) for the generous gift of the G6PASE antibody. We thank the staff members of the following GenoToul core facilities for technical assistance: MetaToul/ Lipidomic, Genome \& Transcriptome, Anexplo/Histopathology and Phenotyping.

\section{References}

1. Grun F, Blumberg B. Endocrine disrupters as obesogens. Mol Cell Endocrinol 2009;304:19-29.

2. Vandenberg LN, Hauser R, Marcus M, Olea N, Welshons WV. Human exposure to bisphenol A (BPA). Reprod Toxicol 2007;24: $139-177$. 
3. Calafat AM, Kuklenyik Z, Reidy JA, Caudill SP, Ekong J, Needham LL. Urinary concentrations of bisphenol A and 4-nonylphenol in a human reference population. Environ Health Perspect 2005;113: 391-395.

4. Richter CA, Birnbaum LS, Farabollini F, Newbold RR, Rubin BS, Talsness CE, et al. In vivo effects of bisphenol A in laboratory rodent studies. Reprod Toxicol 2007;24:199-224.

5. Lang IA, Galloway TS, Scarlett A, Henley WE, Depledge M, Wallace $\mathrm{RB}$, et al. Association of urinary bisphenol A concentration with medical disorders and laboratory abnormalities in adults. JAMA 2008;300: 1303-1310.

6. Melzer D, Rice NE, Lewis C, Henley WE, Galloway TS. Association of urinary bisphenol a concentration with heart disease: evidence from NHANES 2003/06. PLoS One 2010;5:e8673.

7. Rubin BS, Soto AM. Bisphenol A: perinatal exposure and body weight. Mol Cell Endocrinol 2009;304:55-62.

8. Rubin BS, Murray MK, Damassa DA, King JC, Soto AM. Perinatal exposure to low doses of bisphenol A affects body weight, patterns of estrous cyclicity, and plasma LH levels. Environ Health Perspect 2001; 109:675-680.

9. Miyawaki J, Sakayama K, Kato H, Yamamoto H, Masuno H. Perinatal and postnatal exposure to bisphenol a increases adipose tissue mass and serum cholesterol level in mice. J Atheroscler Thromb 2007;14: 245-252.

10. Somm E, Schwitzgebel VM, Toulotte A, Cederroth CR, Combescure $\mathrm{C}$, Nef $\mathrm{S}$, et al. Perinatal exposure to bisphenol a alters early adipogenesis in the rat. Environ Health Perspect 2009;117:1549-1555.

11. Vandenberg LN, Maffini MV, Wadia PR, Sonnenschein C, Rubin BS, Soto AM. Exposure to environmentally relevant doses of the xenoestrogen bisphenol-A alters development of the fetal mouse mammary gland. Endocrinology 2007;148:116-127.

12. Phrakonkham P, Viengchareun S, Belloir C, Lombes M, Artur Y, Canivenc-Lavier MC. Dietary xenoestrogens differentially impair 3T3-L1 preadipocyte differentiation and persistently affect leptin synthesis. J Steroid Biochem Mol Biol 2008;110:95-103.

13. Hugo ER, Brandebourg TD, Woo JG, Loftus J, Alexander JW, BenJonathan N. Bisphenol A at environmentally relevant doses inhibits adiponectin release from human adipose tissue explants and adipocytes. Environ Health Perspect 2008;116:1642-1647.

14. Masuno H, Iwanami J, Kidani T, Sakayama K, Honda K. Bisphenol a accelerates terminal differentiation of 3T3-L1 cells into adipocytes through the phosphatidylinositol 3-kinase pathway. Toxicol Sci 2005; 84:319-327.

15. Masuno H, Kidani T, Sekiya K, Sakayama K, Shiosaka T, Yamamoto $\mathrm{H}$, Honda $\mathrm{K}$. Bisphenol A in combination with insulin can accelerate the conversion of 3T3-L1 fibroblasts to adipocytes. J Lipid Res 2002; 43:676-684.

16. Sargis RM, Johnson DN, Choudhury RA, Brady MJ. Environmental endocrine disruptors promote adipogenesis in the 3T3-L1 cell line through glucocorticoid receptor activation. Obesity (Silver Spring) 2010;18:1283-1288.

17. Nadal A, Alonso-Magdalena P, Soriano S, Quesada I, Ropero AB. The pancreatic beta-cell as a target of estrogens and xenoestrogens: implications for blood glucose homeostasis and diabetes. Mol Cell Endocrinol 2009;304:63-68.

18. Ropero AB, Alonso-Magdalena P, Garcia-Garcia E, Ripoll C, Fuentes E, Nadal A. Bisphenol-A disruption of the endocrine pancreas and blood glucose homeostasis. Int J Androl 2008;31:194-200.

19. Alonso-Magdalena P, Morimoto S, Ripoll C, Fuentes E, Nadal A. The estrogenic effect of bisphenol A disrupts pancreatic beta-cell function in vivo and induces insulin resistance. Environ Health Perspect 2006;114: 106-112.

20. Alonso-Magdalena P, Ropero AB, Carrera MP, Cederroth CR, Baquie $\mathrm{M}$, Gauthier BR, et al. Pancreatic insulin content regulation by the estrogen receptor ER alpha. PLoS One 2008;3:e2069.

21. Alonso-Magdalena P, Vieira E, Soriano S, Menes L, Burks D, Quesada I, et al. Bisphenol A exposure during pregnancy disrupts glucose home- ostasis in mothers and adult male offspring. Environ Health Perspect 2010;118:1243-1250.

22. Ruijter JM, Ramakers C, Hoogaars WM, Karlen Y, Bakker O, van den Hoff MJ, et al. Amplification efficiency: linking baseline and bias in the analysis of quantitative PCR data. Nucleic Acids Res 2009;37: e45.

23. Rajas F, Jourdan-Pineau H, Stefanutti A, Mrad EA, Iynedjian PB, Mithieux G. Immunocytochemical localization of glucose 6-phosphatase and cytosolic phosphoenolpyruvate carboxykinase in gluconeogenic tissues reveals unsuspected metabolic zonation. Histochem Cell Biol 2007; 127:555-565.

24. Zadravec D, Brolinson A, Fisher RM, Carneheim C, Csikasz RI, Bertrand-Michel $\mathrm{J}$, et al. Ablation of the very-long-chain fatty acid elongase ELOVL3 in mice leads to constrained lipid storage and resistance to diet-induced obesity. FASEB J 2010;24:4366-4377.

25. Rotman Y, Koh C, Zmuda JM, Kleiner DE, Liang TJ. The association of genetic variability in patatin-like phospholipase domain-containing protein 3 (PNPLA3) with histological severity of nonalcoholic fatty liver disease. Hepatology 2010;52:894-903.

26. Moreau A, Teruel C, Beylot M, Albalea V, Tamasi V, Umbdenstock T, et al. A novel pregnane X receptor and S14-mediated lipogenic pathway in human hepatocyte. Hepatology 2009;49:2068-2079.

27. Guillou H, Martin PG, Pineau T. Transcriptional regulation of hepatic fatty acid metabolism. Subcell Biochem 2008;49:3-47.

28. Sato R. Sterol metabolism and SREBP activation. Arch Biochem Biophys 2010;501:177-181.

29. Postic C, Dentin R, Denechaud PD, Girard J. ChREBP, a transcriptional regulator of glucose and lipid metabolism. Annu Rev Nutr 2007; 27:179-192.

30. Alonso-Magdalena P, Laribi O, Ropero AB, Fuentes E, Ripoll C, Soria $\mathrm{B}$, et al. Low doses of bisphenol A and diethylstilbestrol impair Ca2+ signals in pancreatic alpha-cells through a nonclassical membrane estrogen receptor within intact islets of Langerhans. Environ Health Perspect 2005;113:969-977.

31. Hanet N, Lancon A, Delmas D, Jannin B, Chagnon MC, CherkaouiMalki $\mathrm{M}$, et al. Effects of endocrine disruptors on genes associated with 17beta-estradiol metabolism and excretion. Steroids 2008;73: 1242-1251.

32. Senafi SB, Clarke DJ, Burchell B. Investigation of the substrate specificity of a cloned expressed human bilirubin UDP-glucuronosyltransferase: UDP-sugar specificity and involvement in steroid and xenobiotic glucuronidation. Biochem J 1994;303(Pt 1):233-240.

33. Hanioka N, Naito T, Narimatsu S. Human UDP-glucuronosyltransferase isoforms involved in bisphenol A glucuronidation. Chemosphere 2008; 74:33-36.

34. Kersten S. Mechanisms of nutritional and hormonal regulation of lipogenesis. EMBO Rep 2001;2:282-286.

35. Foufelle F, Ferre P. New perspectives in the regulation of hepatic glycolytic and lipogenic genes by insulin and glucose: a role for the transcription factor sterol regulatory element binding protein-1c. Biochem J 2002;366:377-391.

36. Chen G, Liang G, Ou J, Goldstein JL, Brown MS. Central role for liver $\mathrm{X}$ receptor in insulin-mediated activation of Srebp-1c transcription and stimulation of fatty acid synthesis in liver. Proc Natl Acad Sci USA 2004;101:11245-11250.

37. Schultz JR, Tu H, Luk A, Repa JJ, Medina JC, Li L, et al. Role of LXRs in control of lipogenesis. Genes Dev 2000;14:2831-2838.

38. Hegarty BD, Bobard A, Hainault I, Ferre P, Bossard P, Foufelle F. Distinct roles of insulin and liver $\mathrm{X}$ receptor in the induction and cleavage of sterol regulatory element-binding protein-1c. Proc Natl Acad Sci U S A 2005;102:791-796.

39. Cha JY, Repa JJ. The liver X receptor (LXR) and hepatic lipogenesis. The carbohydrate-response element-binding protein is a target gene of LXR. J Biol Chem 2007;282:743-751.

40. Brown SB, Maloney M, Kinlaw WB. "Spot 14" protein functions at the pretranslational level in the regulation of hepatic metabolism by thyroid hormone and glucose. J Biol Chem 1997;272:2163-2166. 
41. Kinlaw WB, Church JL, Harmon J, Mariash CN. Direct evidence for a role of the "spot 14" protein in the regulation of lipid synthesis. J Biol Chem 1995;270:16615-16618.

42. Huang Y, He S, Li JZ, Seo YK, Osborne TF, Cohen JC, Hobbs HH. A feed-forward loop amplifies nutritional regulation of PNPLA3. Proc Natl Acad Sci U S A 2010;107:7892-7897.

43. Xie X, Liao H, Dang H, Pang W, Guan Y, Wang X, et al. Down-regulation of hepatic HNF4alpha gene expression during hyperinsulinemia via SREBPs. Mol Endocrinol 2009;23:434-443.

44. Kotzka J, Lehr S, Roth G, Avci H, Knebel B, Muller-Wieland D. Insulin-activated Erk-mitogen-activated protein kinases phosphorylate sterol regulatory element-binding protein-2 at serine residues 432 and 455 in vivo. J Biol Chem 2004;279:22404-22411.
45. Nagai M, Sakakibara J, Nakamura Y, Gejyo F, Ono T. SREBP-2 and NF-Y are involved in the transcriptional regulation of squalene epoxidase. Biochem Biophys Res Commun 2002;295: 74-80.

46. Neuschwander-Tetri BA. Hepatic lipotoxicity and the pathogenesis of nonalcoholic steatohepatitis: the central role of nontriglyceride fatty acid metabolites. Hepatology 2010;52:774-788.

47. Larter CZ, Chitturi S, Heydet D, Farrell GC. A fresh look at NASH pathogenesis. Part 1. The metabolic movers. J Gastroenterol Hepatol 2010;25:672-690.

48. Cave M, Deaciuc I, Mendez C, Song Z, Joshi-Barve S, Barve S, et al. Nonalcoholic fatty liver disease: predisposing factors and the role of nutrition. J Nutr Biochem 2007;18:184-195. 